\title{
STUDIES IN FAT METABOLISM. III. THE EFFECT OF ACTH, OF CORTISONE, AND OF OTHER STEROID COMPOUNDS UPON FASTING-INDUCED HYPERKETONEMIA AND KETONURIA 1, 2,
}

\author{
By LAURANCE W. KINSELL, SHELDON MARGEN, GEORGE D. MICHAELS, \\ ROBERT REISS, ROBERT FRANTZ, AND JOHN CARBONE, WITH THE \\ TECH NICAL ASSISTANCE OF JUDITH LANGE AND GERALD LIEBERT
}

(From the Institute for Metabolic Research, Highland Alameda County Hospital, Oakland, Cal.)

(Submitted for publication June 18, 1951; accepted August 27, 1951)

As previously described (1), testosterone propionate appears to have a direct or indirect effect upon fat metabolism. The present study was initiated for the purpose of evaluating further the effect of testosterone and of other hormonal entities upon fat metabolism.

A standard fasting technique was devised as a reasonably simple method of inducing hyperketonemia. Initially, patients were fasted for two and one-half days, and subsequently for three and one-half days. As expected, almost all individuals had a progressive rise in blood and urinary ketone bodies during the period of the fast. Each individual was used as his own control, that is to say one or more control fasts were carried out during which time no treatment was administered. Subsequently, one or more identical fasts were carried out during which time the patient was treated with specific hormonal agents.

\section{METHODS}

In addition to blood and urinary ketones, urinary nitrogen, sodium, potassium, and 17-ketosteroids have been determined, as well as blood sugar, serum phosphorus, and circulating eosinophil levels. Urinary nitrogen has been determined by the Kirk modification of the Kjeldahl procedure (2). Urinary sodium and potassium have been quantitated using the Beckman flame photometer. Blood and urinary ketones have been determined by the

1 This work is supported in part by grants from the Pharmaceutical and Research Divisions, Armour and Company, and from the Office of Naval Research.

2 A portion of this work was carried out on the wards of the hospital of the University of California Medical School, San Francisco.

3 A portion of this work appears in the Proceedings of the Second Clinical ACTH Conference, Volume I-Research, John R. Mote, Ed., Blakiston Co., 1951, pages 308-317. method of Michaels and associates (3) ; serum phosphorus by the method of Fiske and SubbaRow (4); blood sugar by the method of Giragossintz, Davidson and Kirk (5) ; and circulating eosoinophils by the method of Randolph (6).

\section{RESULTS}

A total of more than 150 fasts in more than 50 patients have been carried out to date. As noted above, the procedure initially consisted of a two day fast. In Figure 1 is shown a summary of some of the findings in the first patient in whom the fasting procedure was instituted, a 45 year old male with relatively mild diabetes mellitus. This patient, at the time that the studies were first begun, had received no insulin at any time. He had an initial fasting blood sugar which approached $250 \mathrm{mg} . / 100 \mathrm{cc}$., and a fasting blood ketone level of approximately $10 \mathrm{mg} . / 100 \mathrm{cc}$. (normal value less than $1 \mathrm{mg} . / 100 \mathrm{cc}$.). During the first two and onehalf day fast, the patient, after an initial fall in blood ketones, had a progressive rise to a level in excess of $30 \mathrm{mg} . / 100 \mathrm{cc}$. Also during the first 36 hours, there was a fall in blood sugar from his original level to values of less than $150 \mathrm{mg} . / 100 \mathrm{cc}$.

The second fast was carried out a week later. It is of interest that following the initial fast, this man's fasting blood sugar values remained below $200 \mathrm{mg} . / 100 \mathrm{cc}$. Testosterone propionate ${ }^{4}$ was administered in a dosage of $100 \mathrm{mg}$. daily beginning four days before fast No, 2. During this fast, the blood sugar values fell to completely normal levels (normal range for this method varies from 60 to $100 \mathrm{mg} . / 100 \mathrm{cc}$.). Initial fasting blood ketones were in a normal range and rose progres-

\footnotetext{
4 Grateful acknowledgment is made to Dr. Edward Henderson of the Schering Corporation for supplies of testosterone propionate.
} 


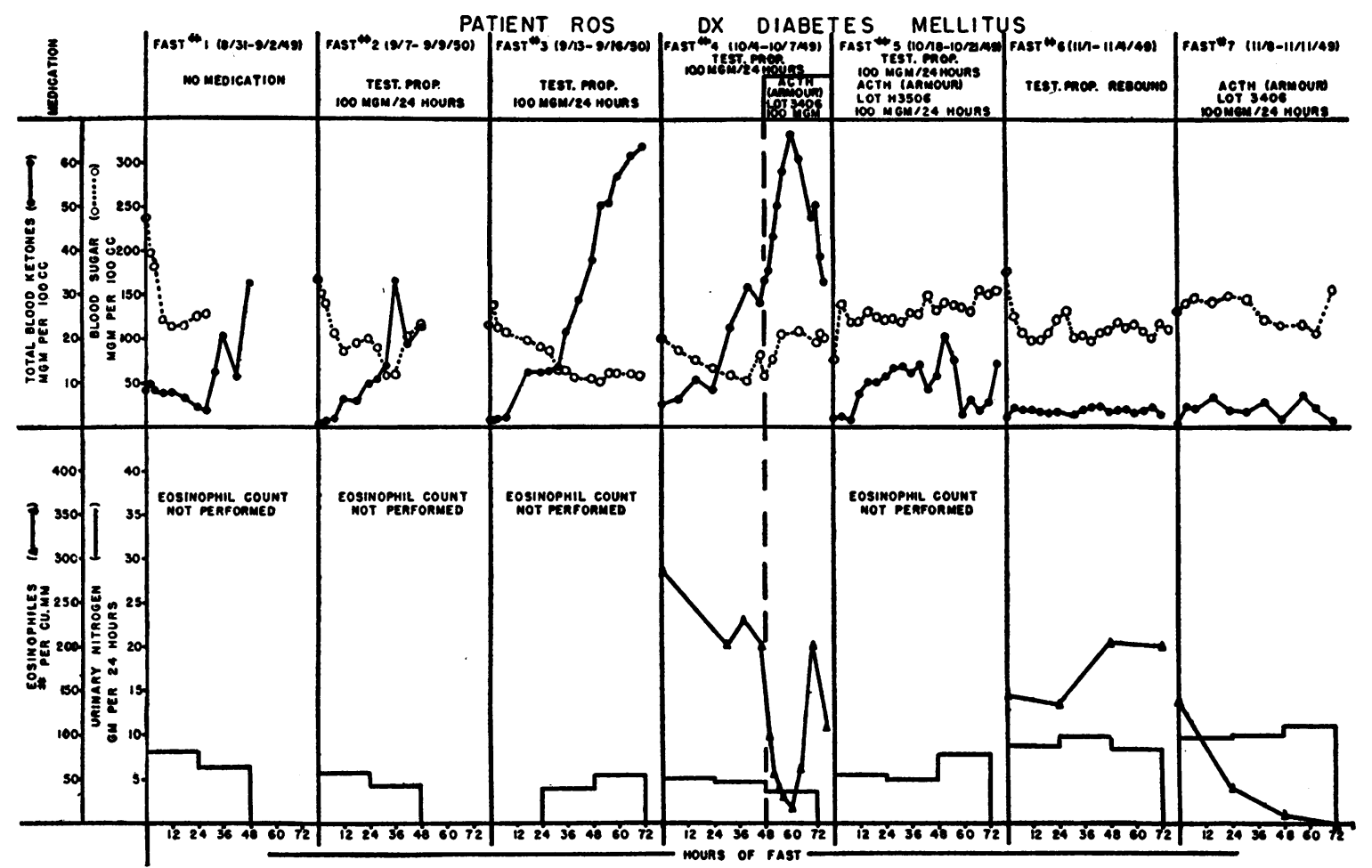

Fig. 1. Effect of Testosterone Propionate and of ACTH upon Fasting-Induced Hyperketonemia in a Patrent with Mild Diabetes Mellitus

It is apparent that: a. Testosterone propionate did not significantly modify the fasting-induced hyperketonemia. b. ACTH depressed to a marked degree the fasting-induced hyperketonemia. c. Fasting-induced hyperketonemia was greatly depressed during the period of "testosterone rebound."

sively during the two and one-half days of the fast. The urinary nitrogen excretion was significantly less during this fast as compared with fast No. 1. Testosterone propionate was administered continuously in the dosage above noted over the next several weeks (until the completion of fast No. 5).

Fast No. 3 was carried out over a period of 72 hours. At the end of this period, the fasting blood ketones exceeded $60 \mathrm{mg} . / 100 \mathrm{cc}$.

During the last 24 hours of fast No. 4, the patient received $25 \mathrm{mg}$. of $\mathrm{ACTH}^{\mathrm{s}}$ intramuscularly every two hours for four doses (first dose at 48th hour of fast). The blood ketones which had risen precipitously, as in fast No. 3 , fell from a level of $68 \mathrm{mg}$. \% to $28 \mathrm{mg}$. \% during the last 18 hours of the fast. No increase in urinary nitrogen occurred despite the ACTH administration.

During fast No. 5 , the patient continued to re-

${ }^{5}$ Grateful acknowledgment is made to Dr. John $R$. Mote of the Armour Laboratories for supplies of ACTH. ceive testosterone and also received $\mathrm{ACTH}-25$ mg. every six hours during the period $10 / 18$ to 10/21. The blood ketones at no time exceeded $20 \mathrm{mg} . / 100 \mathrm{cc}$. Urine nitrogen excretion was higher than during the fast on testosterone alone, and the blood sugars rose to levels approaching $150 \mathrm{mg} . / 100 \mathrm{cc}$.

On October 28, testosterone was discontinued; and fast No. 6 was performed during the period of November 1st to 4th. During this period of "testosterone rebound" (that is during the period of increased protein catabolism which always occurs when testosterone is discontinued), the blood ketone levels remained below $5 \mathrm{mg} . / 100 \mathrm{cc}$. throughout the entire fast; the urine nitrogens remained high; and the blood sugar levels averaged $100 \mathrm{mg} . / 100 \mathrm{cc}$. There was no fall in circulating eosinophils.

The final fast (No. 7) was performed one week later during which time the patient again received $25 \mathrm{mg}$. of ACTH every six hours throughout the 


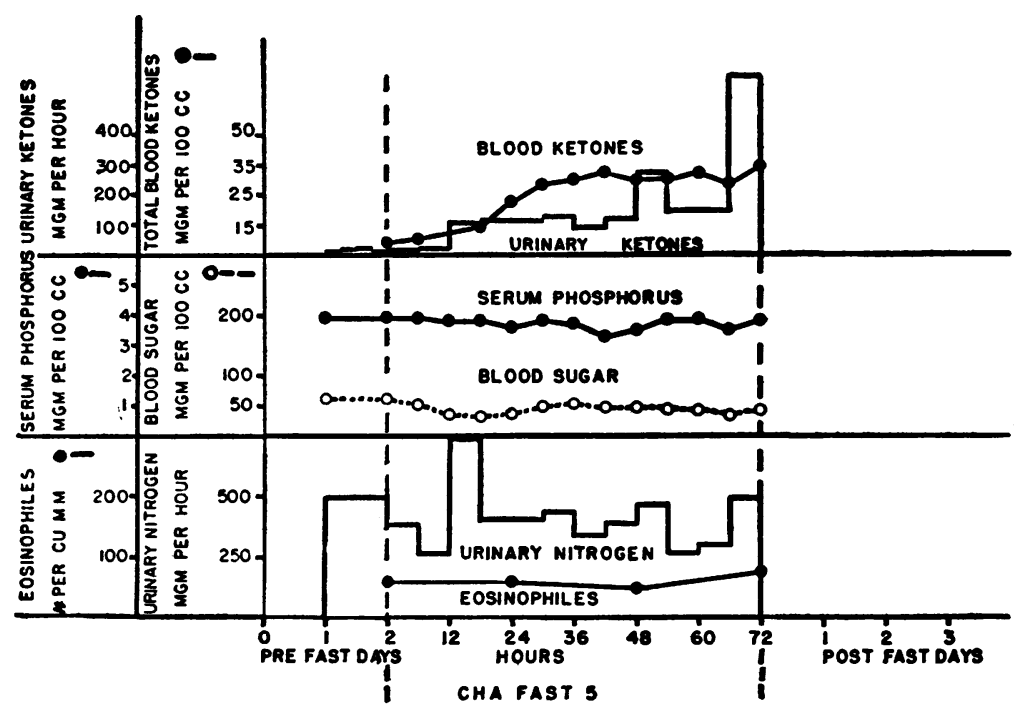

Fig. 2. Control Fast in a "Normal" Obese Male

period November 8th to November 11th. No other medication was administered. The blood ketone values during this fast were comparable to those during the period of "testosterone rebound." The blood sugars and the urinary nitrogens were slightly higher; and the circulating eosinophils fell to 0 , indicating an adequate adrenal response to the administered ACTH.

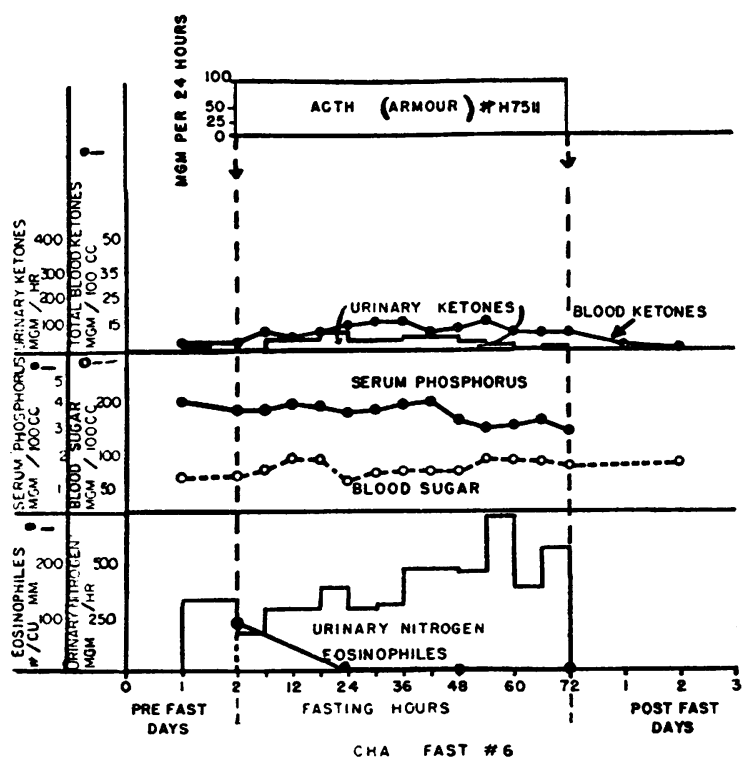

Fig. 3. Fast with aCth in the Same Patient Shown IN Figure 2

The marked decrease in hyperketonemia and ketonuria is apparent.
A large group of patients without evidence of any endocrine abnormality has been studied in the manner indicated above. In Figures 2 and 3 are shown the values obtained during a control fast and during a fast with ACTH treatment (25 mg. every six hours) in a man with simple exogenous obesity. During the control fast the blood ketones rose to levels approximating $35 \mathrm{mg} . / 100$ cc. An identical fast carried out in conjunction with ACTH administration resulted in final blood ketone values which were less than $10 \mathrm{mg} . / 100 \mathrm{cc}$. The urinary ketone excretion was proportional to the blood levels. Blood sugar levels were significantly lower during the control fast than during ACTH administration. Urinary nitrogen values tended to be relatively constant during the control fast, and to rise during the fast with ACTH. An excellent eosinophil response was observed during the "ACTH fast."

In Figure 4 are shown serial studies in a young male suffering from rheumatoid arthritis. During control fast No. 1 (August 29-September 1), his blood ketones rose to values in excess of $40 \mathrm{mg}$./ $100 \mathrm{cc}$., and his blood sugars fell.

ACTH in the usual dosage (100 mg. daily) was begun on September 12th. During fast No. 2 (September 12-15), the fasting blood ketones did not exceed $15 \mathrm{mg} . / 100 \mathrm{cc}$. A third fast carried out two weeks later (during which time the patient had received $\mathrm{ACTH}$ continuously) showed a maximal blood ketone value only slightly in ex- 


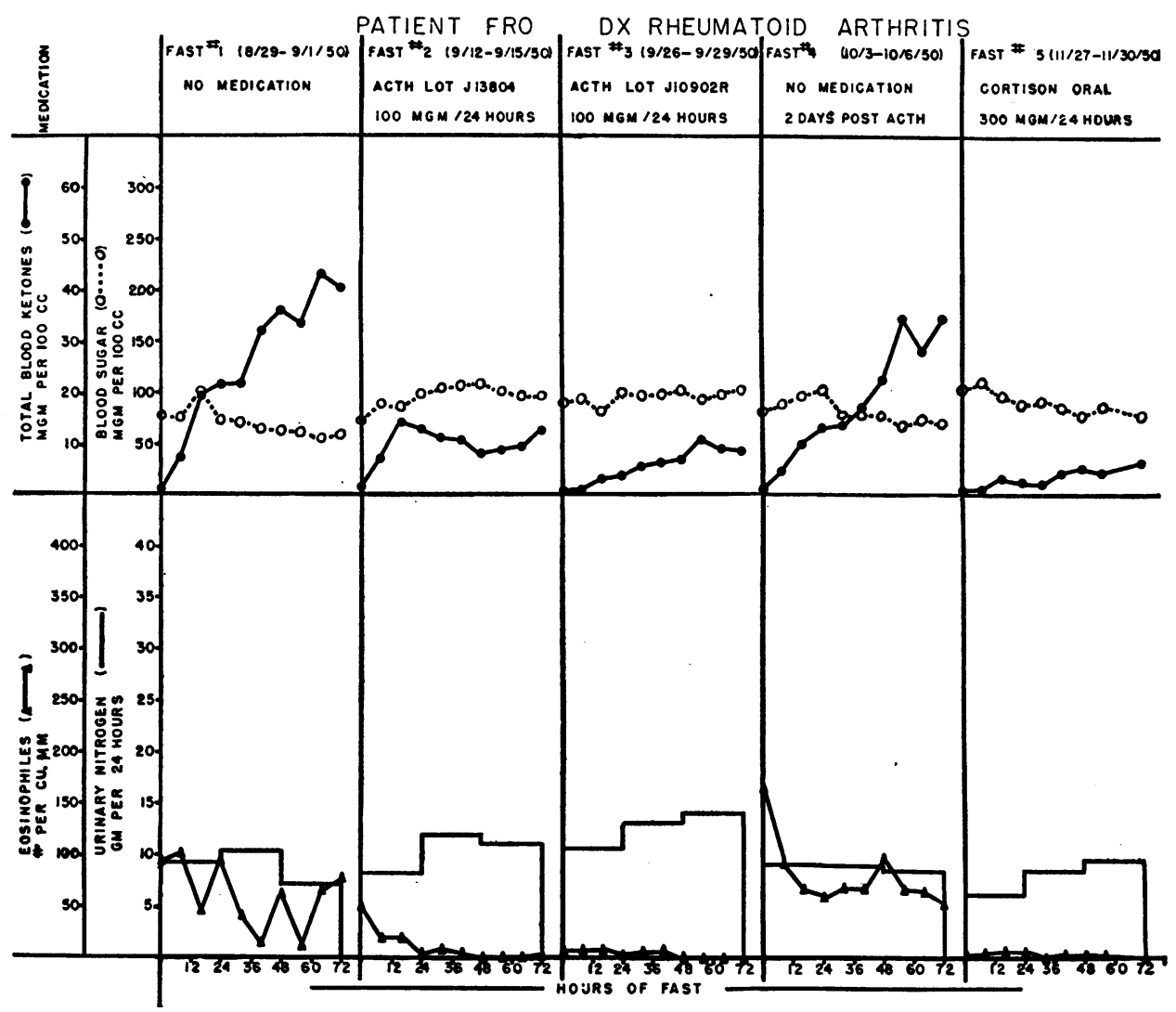

Fig. 4. Serial Fasting Studies in a Young Male Patient with Rheumatoid Arthritis Both ACTH and cortisone greatly diminish the fasting-induced hyperketonemia.

cess of $10 \mathrm{mg} . / 100 \mathrm{cc}$., and an average level much below this.

Fast No. 4 carried out two days after discontinuance of $\mathrm{ACTH}$ resulted in a rise of blood ketones to approximately $35 \mathrm{mg} . / 100 \mathrm{cc}$. on the third day.

Fast No. 5 carried out six weeks later, during which time oral cortisone ${ }^{6}$ was administered continuously in a dosage of $300 \mathrm{mg} . / 24$ hours, resulted in maximal blood ketone levels well below $10 \mathrm{mg} . / 100 \mathrm{cc}$.

Fasting alone was associated with a tendency to fall in circulating eosinophils, but the magnitude of this fall was not comparable with that resulting from ACTH and cortisone. Urinary nitrogen excretion and blood sugar levels were significantly higher during the fasts associated with $\mathrm{ACTH}$ administration.

- Grateful acknowledgment is made to Dr. Augustus Gibson of Merck \& Company for supplies of cortisone and Compound A.
The findings in this patient are characteristic of those observed in more than 20 individuals with rheumatoid arthritis who have been so studied (with the exception of patient Lew noted below), and also characteristic of the other individuals studied excepting those with specific endocrinopathies (see below).

In Figure 5 are shown the findings in a patient with rheumatoid arthritis, whose ketone response is the only exceptional one thus far encountered. There were other bizarre features in his pattern of ACTH response. During fast No. 1, this patient had a maximal rise in blood ketones to values approximating $35 \mathrm{mg} . / 100 \mathrm{cc}$.

During fast No. 2, the patient received gradually increasing amounts of ACTH (caution was exercised because of the presence of glaucoma). A significant fall in eosinophils occurred but the maximal level of ketones was actually higher than during the control fast.

During fast No. 3, the patient received the usual 
dosage of $100 \mathrm{mg}$. of ACTH daily (and also was pretreated with his material). He again had a progressive elevation of blood ketones which significantly exceeded that obtained during the control fast. During this period of ACTH administration, no fall in eosinophils occurred. On the other hand, there appeared to be no question that adrenal stimulation was obtained, in view of the very high 17-ketosteroid values and the evidence of marked sodium retention. It is of interest also that this patient made a minimal clinical response to ACTH administration. One might conjecture that this man's adrenals produced unusual steroids in response to ACTH treatment.

In Figure 6 is shown the response pattern in a female patient with monocytic leukemia. The characteristic suppression of hyperketonemia and

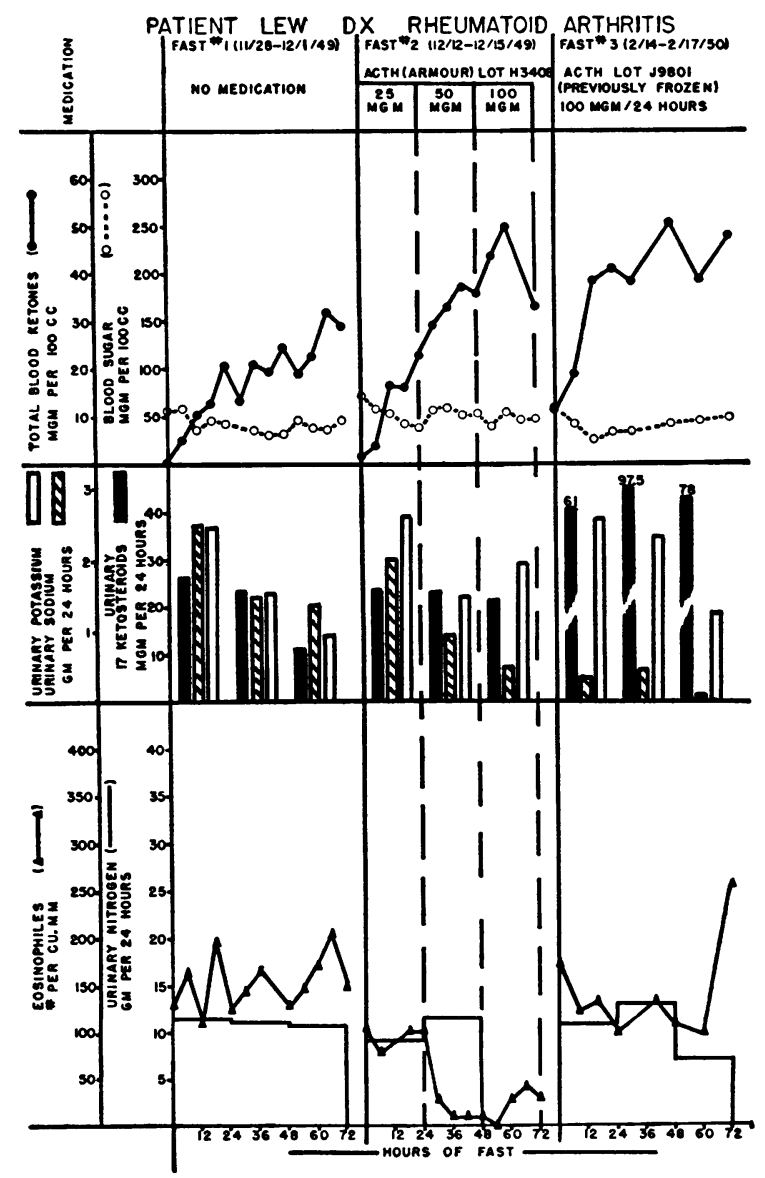

Fig. 5. Fasting Studies in an "ACTH-Resistant Patient” with Rhéumatoid Arthritis

The findings would suggest some bizarre type of adrenal cortical response to the administered ACTH. hyperketonuria was observed in this patient together with an increase in urinary 17-ketosteroid excretion and urinary nitrogen excretion. No fall in circulating eosinophils was obtained, presumably because of the abnormal condition of the bone marrow in this individual.

In Figure 7 are shown the findings in a patient with a syndrome characterized by insulin resistant diabetes, hirsutism, amenorrhea, and the lack of any spontaneous ketonuria despite a blood sugar which was constantly in excess of $300 \mathrm{mg} . / 100 \mathrm{cc}^{7}$ ( $T$ his patient on one occasion received in excess of 20,000 units of crystalline insulin intravenously in a space of 24 hours without any fall in blood sugar occurring.)

During the control fast in this girl, the blood and urinary ketones remained at levels only slightly in excess of normal. The blood sugar values actually rose (instead of falling as is the usual observation in the control fasts). The urinary nitrogens remained low and the circulating eosinophils were at all times at a level compatible with considerable adrenocortical stimulation. Urinary 17-ketosteroids were not elevated.

During ACTH administration, it will be noted that blood and urinary ketones were actually increased over the control level. This same statement applies to the blood sugar levels and urinary nitrogen excretion. The rise in 17-ketosteroid excretion and fall in circulating eosinophils to 0 would be compatible with adrenocortical response to the administered ACTH.

This patient subsequently had an exploratory laparotomy which revealed the presence of large polycystic ovaries but failed to reveal evidence of tumor of either adrenal gland. Unfortunately the surgeon did not obtain a biopsy of the adrenal at the time of surgery. Both ovaries were removed without any detectable alteration in the clinical or biochemical status of the patient. Menopausal symptoms did not ensue, nor did the characteristics of her diabetes change.

It seems probable to us that this patient has some variety of adrenal hyperplasia secondary to pituitary pathology which accounts for all of her metabolic and clinical abnormalities.

In Figure 8 are shown the findings in a young

7 We are indebted to Dr. Myron Arrick for the opportunity to study this patient. 


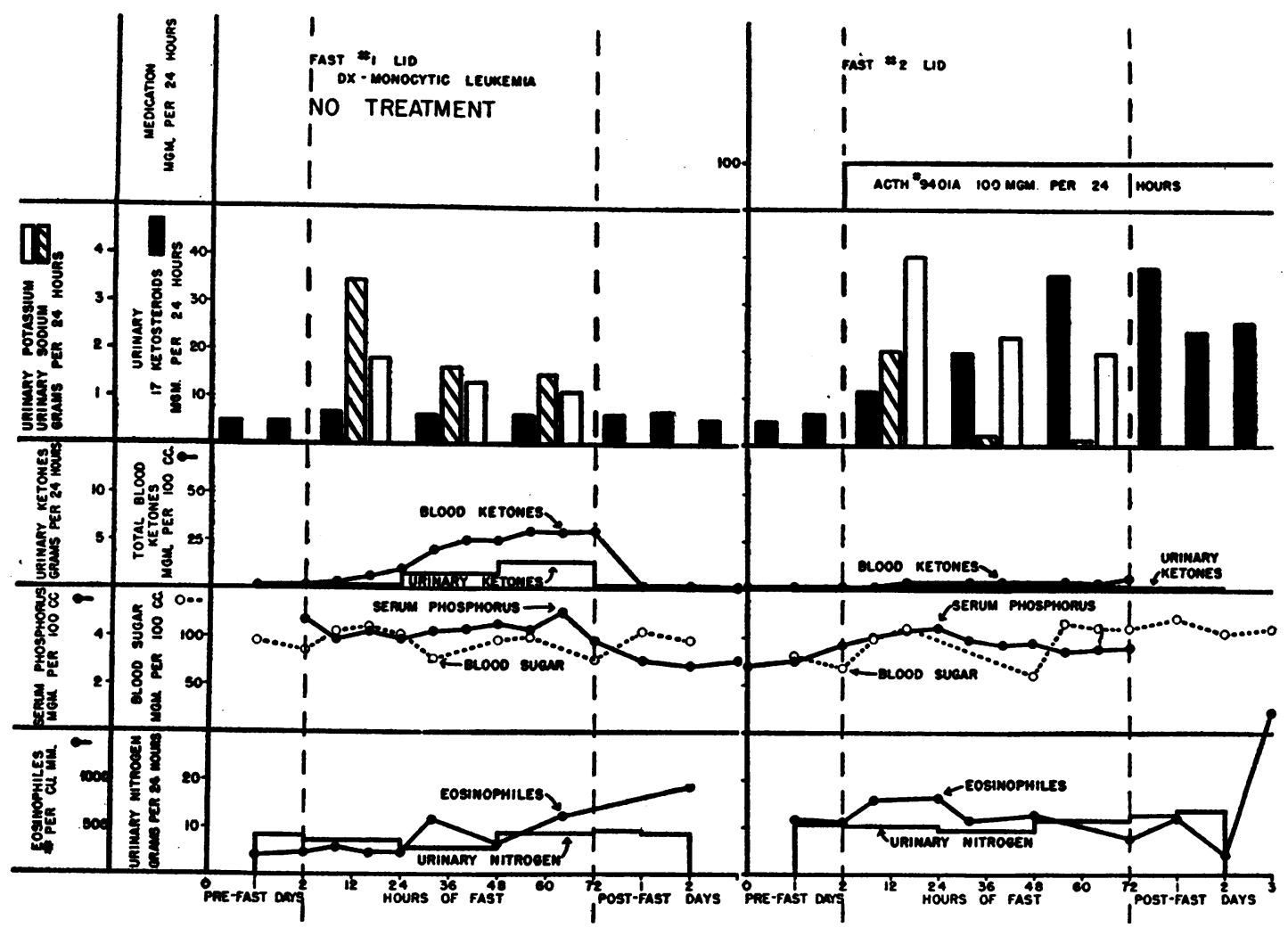

Fig. 6. Fasting Studies in a Patient with Monocytic Leukemia

The effect of ACTH upon blood ketones is in accord with the observations in other patients studied.

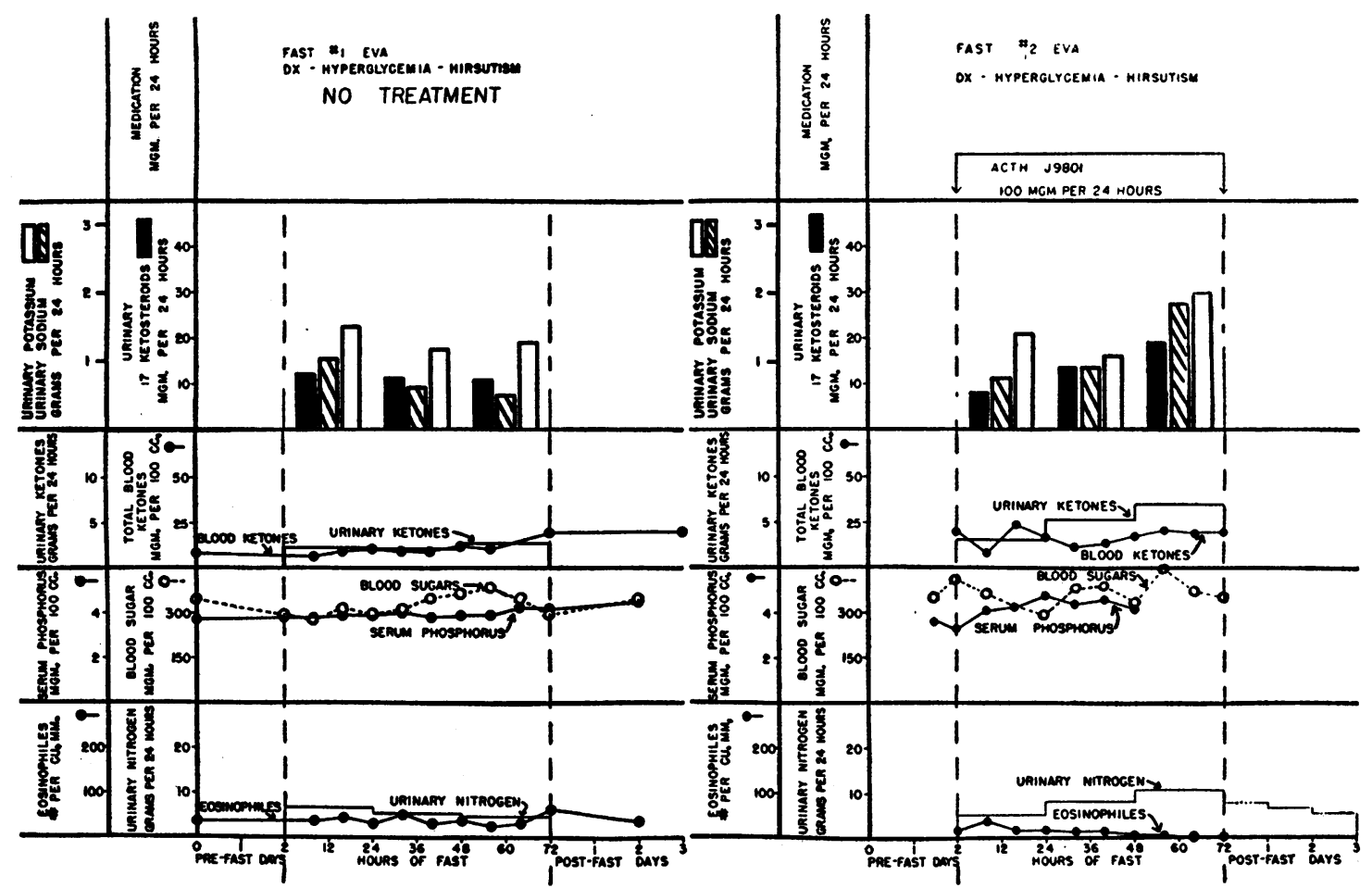

Fig. 7. Fasting Studies in a Patient Suffering from Insulin-Resistant Diabetes, Hirsutism, Obesity, and Amenorrhea

The findings would suggest that this patient has some variety of adrenocortical hyperplasia. She does not have Cushing's syndrome, nor does she have typical adrenogenital syndrome. 


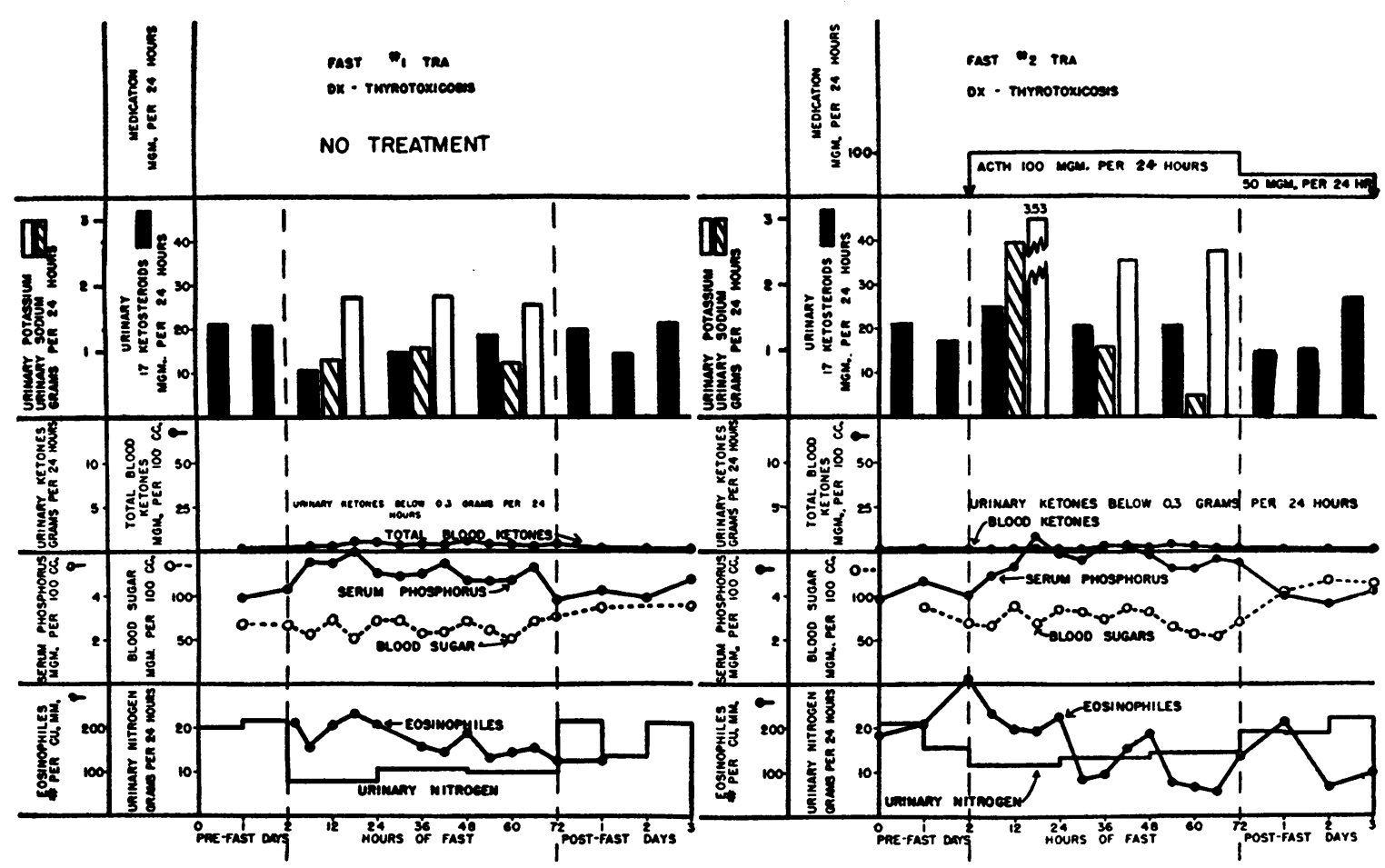

Fig. 8. Fasting Studies in a Young Male Patient with Thyrotoxicosis

Fasting with or without ACTH failed to produce a hyperketonemia in this patient.

male patient with severe thyrotoxicosis. We had anticipated that the fasting-induced hyperketonemia in this patient would be most excessive; instead, essentially no elevation in blood ketones was obtained during either the control fast or the fast during which ACTH was administered. Except for an increase in urinary nitrogen, an elevation in serum phosphorus, and a significant change in the pattern of urinary sodium and potassium and 17-ketosteroid excretion, the findings in the two fasts were essentially identical. One might postulate that a patient with thyrotoxicosis would have sufficient adrenal cortical hyperplasia to account for these findings. The relatively high eosinophil level and the rather poor response of eosinophils to administered ACTH would not agree too well with this concept. An alternative hypothesis would be that hyperthyroidism per se is associated with an increased rate of utilization of ketones. ${ }^{8}$

In Figures 9 and 10 are shown four fasting stud-

8 Since the submission of this paper a "control" fast, carried out in a female hyperthyroid patient, resulted in the usual picture of marked hyperketonemia. ies obtained in a female patient with active acromegaly. A number of interesting and not readily explainable changes were observed in this patient.

These findings may be summarized as follows:

1. Blood ketones. The "usual" suppression of hyperketonemia was obtained with ACTH, but apparent accentuation of hyperketonemia occurred during cortisone administration. Testosterone propionate appeared to diminish the early phase of ketone elevation, but did not modify the eventual hyperketonemia.

2. Circulating eosinophils disappeared completely in response to ACTH and fell markedly during fasting alone and during cortisone administration.

3. Serum phosphorus. As in the case of most acromegalics, this was elevated initially. It rose to extremely high levels during the control fast. It fell during the administration of ACTH, of cortisone, and of testosterone.

4. Blood sugar. This was slightly elevated initially. It fell in a marked degree during the control fast; during the "testosterone fast"; tended to 


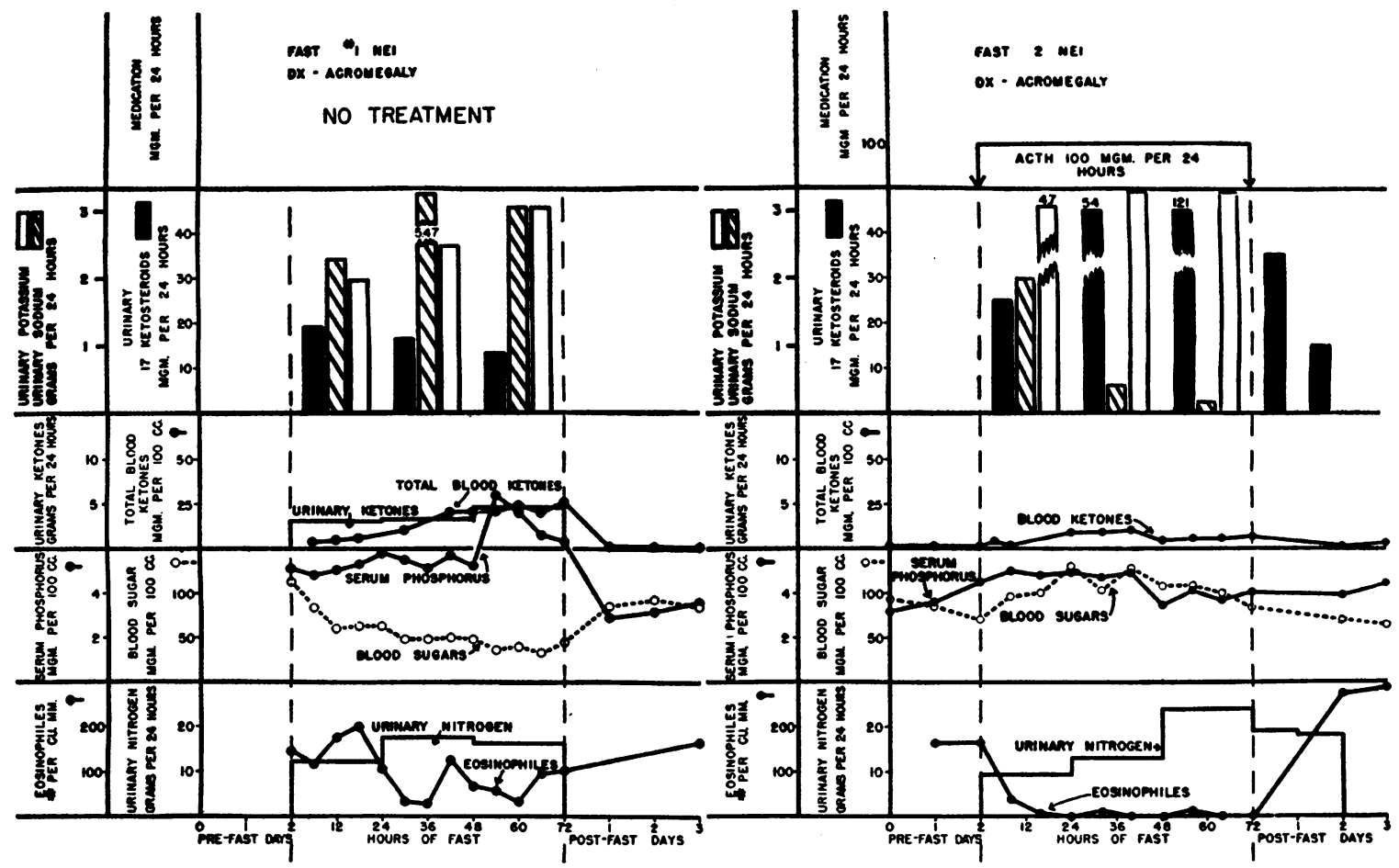

Fig. 9. Fasting Studies in a Female Patient with Acromegaly

The usual effect of ACTH upon blood ketones is observed.

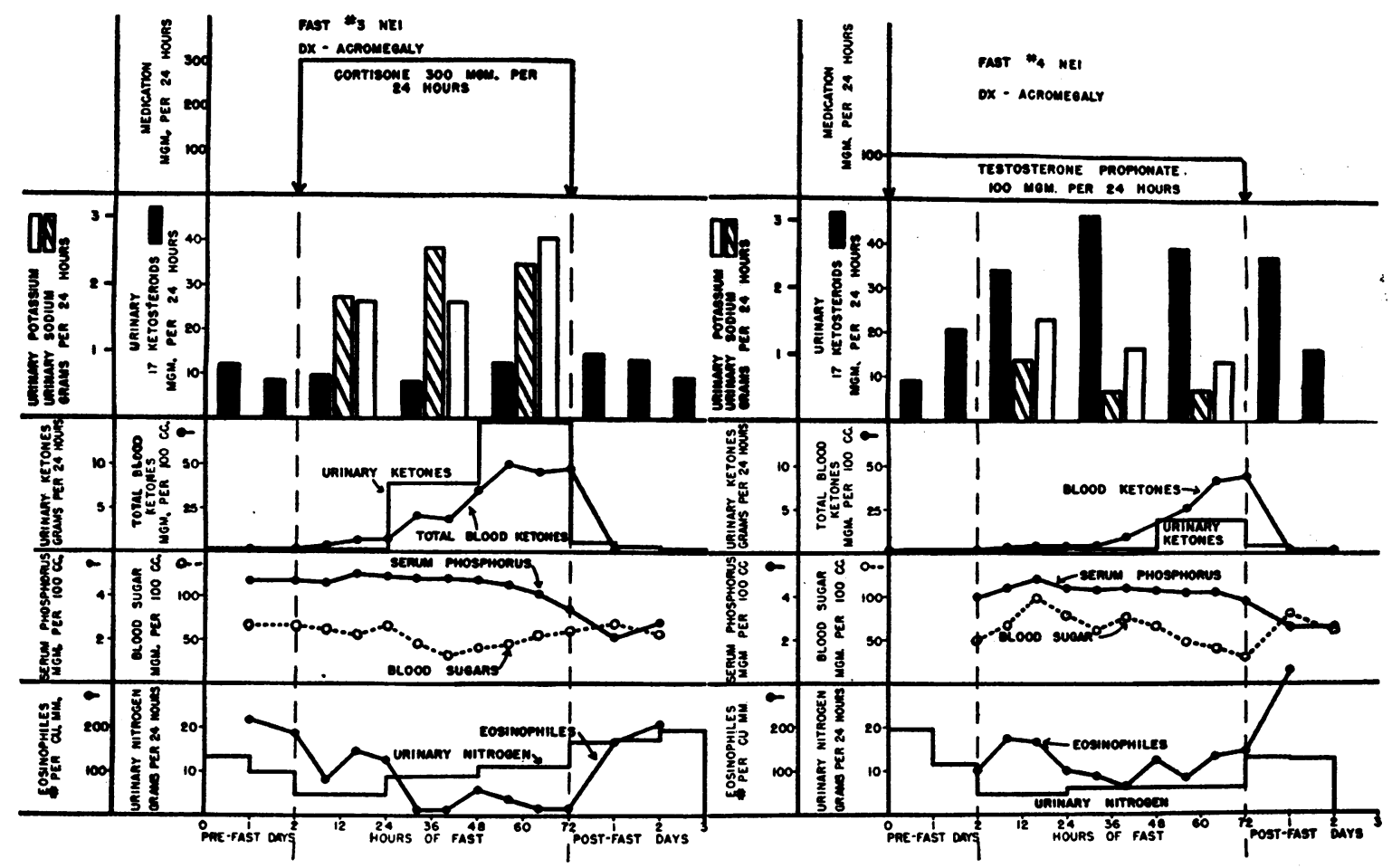

Fig. 10. Fasting Studies in the Same Acromegalic Patient

Cortisone in this patient appeared to accentuate rather than to depress the hyperketonemia. Testosterone may have delayed the elevation in blood ketones, but did not prevent the high level on the third day. 


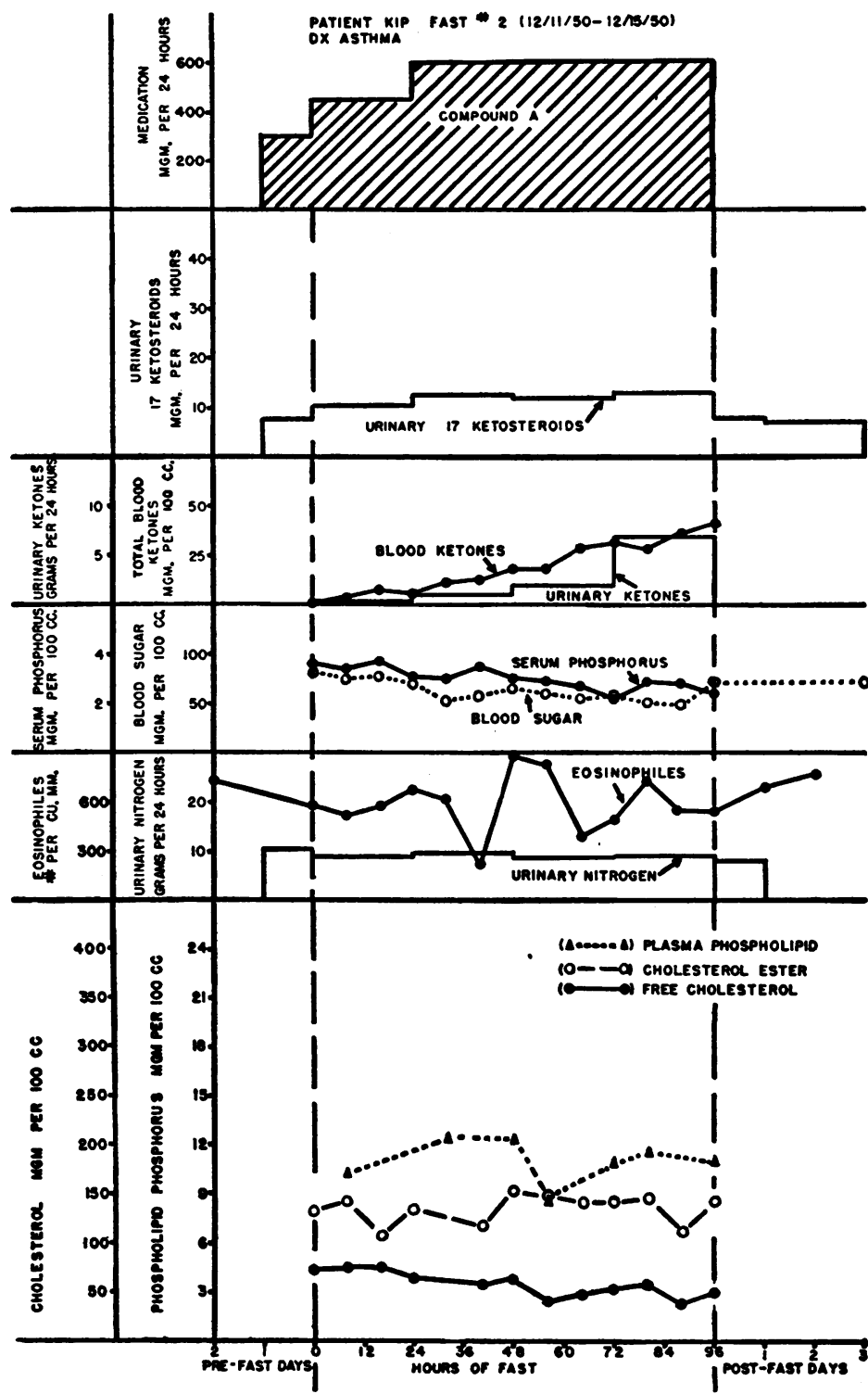

Fig. 11. EFfect of Compound A (11-DEH ydrocorticosterone) UPON FASTING-INDUCED HYPERKETONEMIA

No metabolic effect of this preparation in a dosage of $600 \mathrm{mg}$. a day could be observed.

fall during cortisone administration; and rose significantly during ACTH administration.

5. Urinary nitrogen was highest during $\mathrm{ACTH}$ administration and lowest during testosterone administration, as one would expect.

6. Urinary 17-ketosteroids rose to the highest levels we have observed in anyone with this dosage of $\mathrm{ACTH}$ (121 mg./24 hr. during the third day of ACTH administration).
7. Urinary sodium was excreted in large amounts during the control fast and during cortisone administration; and was retained during ACTH and testosterone administration.

8. Urinary potassium was excreted in very large amounts during the administration of ACTH.

We have not been able to arrive at a satisfactory explanation for the differences in blood ketones 


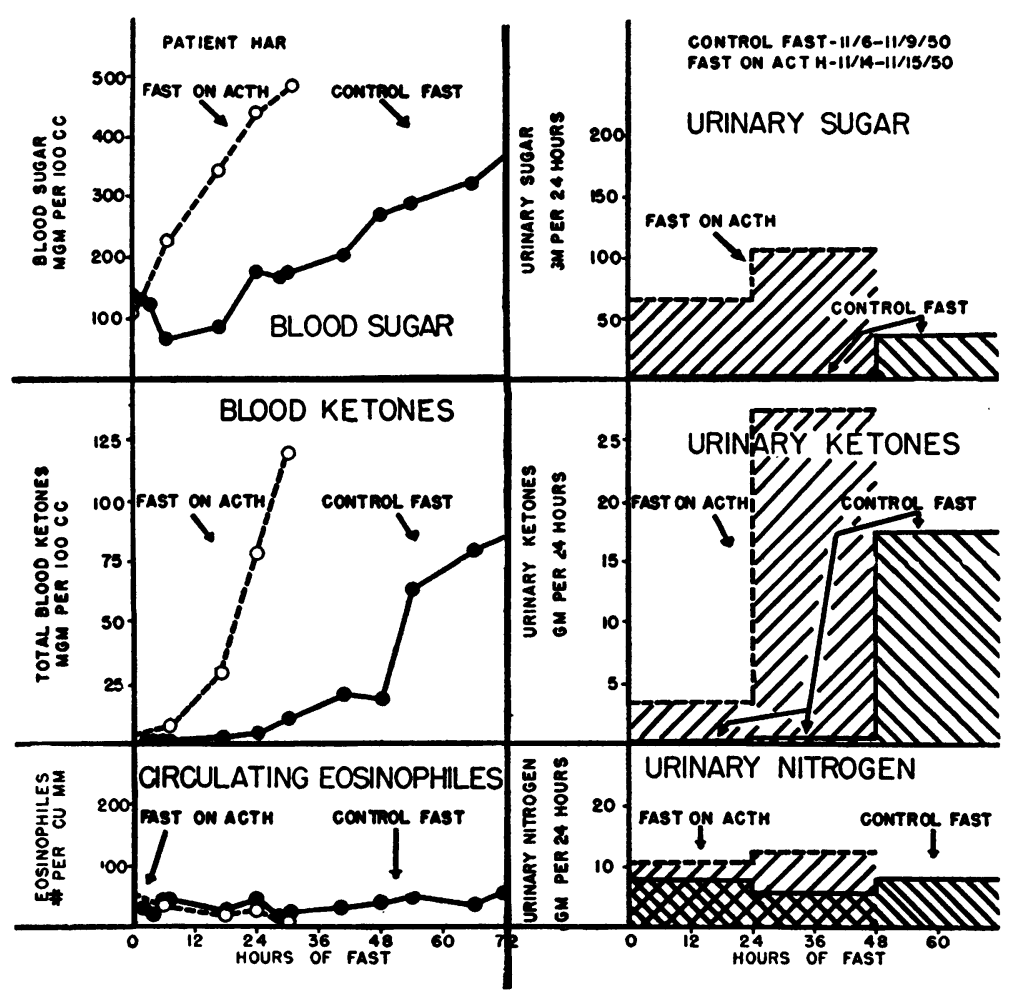

Fig. 12. Effect of ACTH upon Fasting-Induced Hyperketonemia in a Severe Diabetic

Two findings are of interest: 1 . ACTH did not prevent hyperketonemia for reasons which will be discussed elsewhere. 2. The amount of urinary sugar is greater than can be accounted for on the basis of urinary nitrogen. No emphasis is placed upon this finding because of the possibility of endogenous stores of glycogen contributing to the urinary hexose.

during ACTH and cortisone administration respectively. All other patients, so far studied who have received cortisone, have had the same ketone response to this material as has been noted with ACTH.

In Figure 11 are shown the findings during a fast associated with the administration of $600 \mathrm{mg}$. of Compound A daily. This same patient had a very usual response to $\mathrm{ACTH}$ administration in terms of all entities studied. One may, therefore, assume that Compound $\mathrm{A}$ in this dosage has no effect upon urinary 17-ketosteroids, blood ketones, serum phosphorus, blood sugar, circulating eosinophils, or urinary nitrogen.

For reasons which will be discussed presently, it was desired to determine the effect of ACTH upon fasting-induced hyperketonemia in a patient with relatively severe diabetes. In Figure 12 are shown the composite findings of an attempted study in a girl of 19 who required 80 units of insulin daily on an average diet.

During the control fast, the blood sugar which fell initially (as the result of residual effect of protamine zinc insulin) had reached levels in excess of $350 \mathrm{mg} . / 100 \mathrm{cc}$. by the end of the third day. The blood ketone levels exceeded $75 \mathrm{mg} . / 100 \mathrm{cc}$. at this same time.

When ACTH was administered in a dosage of $25 \mathrm{mg}$. every six hours during the second fast, an extremely rapid rise in blood sugar followed by an equally rapid rise in blood ketones occurred. The study was of necessity terminated in the early part of the second day because of the occurrence of progressive dehydration and acidosis. It is interesting that in this patient the increase in urinary sugar considerably exceeded the expected increase on the basis of urinary nitrogen (see below). In Figure 13 are shown 20 blood ketone levels 


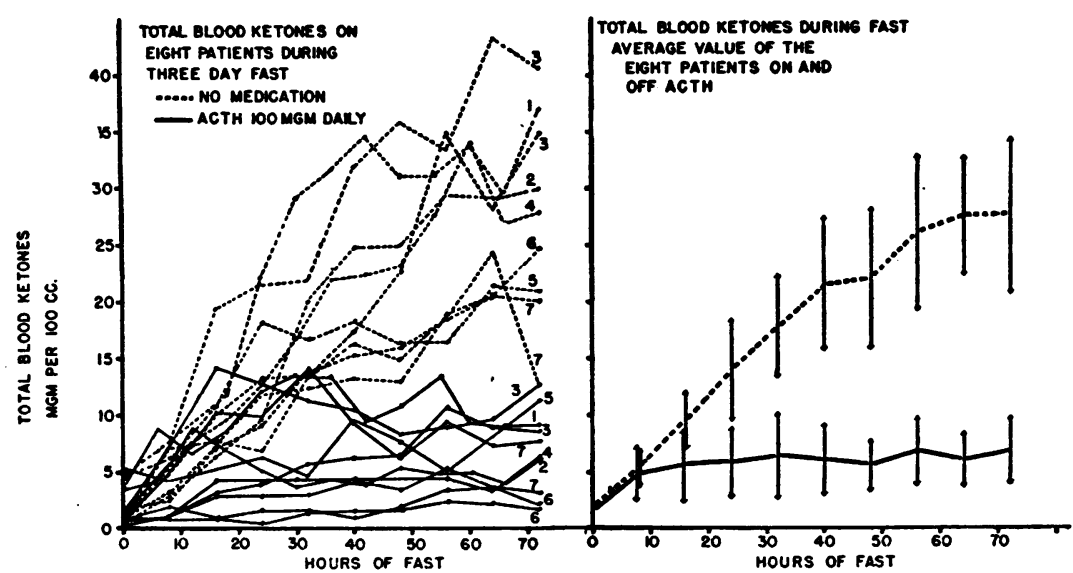

Fig. 13. ACTH Effect upon Fasting-Induced Hyperketonemia (ComPOSITE OF 20 FASTS)

The suppression of fasting-induced hyperketonemia by ACTH is obvious.

obtained in eight patients during standard fasts with and without ACTH. These values were taken at random from studies on individuals without endocrinopathies. The suppressing effect of ACTH upon fasting-induced hyperketonemia is apparent.

\section{DISCUSSION}

From the foregoing data, certain deductions appear to be warranted:

1. The administration of adequate amounts of ACTH or of cortisone to the majority of fasting individuals (without pre-existing endocrinopathies) results in partial or complete suppression of the fasting-induced hyperketonemia.

2. This suppression is usually associated with an elevation of blood sugar and an increase in urinary nitrogen.

3. The total increase in urinary nitrogen is usually of small magnitude; that is, it would not appear to be adequate in amount to explain any major "fat sparing effect" during the period of fast.

4. During the administration of $\mathrm{ACTH}$ and cortisone, there is no decrease in energy requirement; if anything, the oxygen utilization increases.

5. From the foregoing, it would appear that the suppression of fasting-induced hyperketonemia by ACTH and certain adrenal steroids can only have a limited number of explanations. Among these would be the following: a. That one or more adrenal steroids increase the rate of utilization of ketones by peripheral tissues.

$b$. That one or more adrenal steroids decrease the rate of formation of ketones from fatty acids, and at the same time increase the rate of direct utilization of fatty acids for energy purposes by peripheral tissues.

c. That certain adrenal steroids so change the metabolic pathway of fatty acids, that mid-zone metabolites other than ketones are formed. Among such possible metabolites would be hexose.

Other reports from this laboratory, dealing with the rate of utilization of intravenously administered ketones and of intravenously administered fatty acids in the human subject under controlled conditions with and without $\mathrm{ACTH}$, cortisone, and other adrenal steroid administration, will subsequently be presented. It is the purpose of this paper only to indicate that such substances do, in a very significant way, influence the metabolism of fat, and to suggest some of the ways in which such metabolic modification could be accomplished.

If one examines the findings in diabetic patient Har (Figure 12), he finds that during the first two days of the "ACTH fast" the total amount of nitrogen excreted was slightly in excess of 23 gm., and that the total amount of glucose excreted was slightly in excess of $200 \mathrm{gm}$. On the basis of a $\mathrm{D} / \mathrm{N}$ ratio of 3.65 , the maximal amount of carbohydrate which could have been derived from 
protein during this period would be $84 \mathrm{gm}$. This leaves $116 \mathrm{gm}$. of carbohydrate not accounted for by urinary nitrogen. This finding would at least be compatible with the concept that a portion of the effect of adrenal steroids is that of acceleration of neoglucogenesis from fat. It is recognized that in this patient, storage glycogen may have contributed in some measure to the excreted carbohydrate. The findings in this patient will be discussed in more detail in another paper in this series dealing with studies in diabetics on pure fat intake. Whatever the final explanation may be, there appears to be no question that one or more adrenal steroids exert profound effects upon fat metabolism.

\section{SUM M ARY}

1. Total fasting over a period of three and onehalf days results in significant hyperketonemia and ketonuria in the majority of subjects studied.

2. The administration of ACTH and cortisone in adequate amounts results in partial or complete suppression of such fasting-induced hyperketonemia and ketonuria.
3. It appears that such an effect can be accounted for only on the basis of modification of the metabolic pathways of fat.

4. The possible modifications which might occur are considered.

\section{REFERENCES}

1. Kinsell, L. W., Margen, S., and Michaels, G. D., A consideration of the effect of testosterone propionate upon ketone metabolism. Proc. Am. Diabetes A., 1949, 9, 123.

2. Kirk, P. L., A one-piece glass micro-Kjeldahl distillation apparatus. Indust. \& Engin. Chem., Analyt. Ed., 1936, 8, 223.

3. Michaels, G. D., Margen, S., Liebert, G., and Kinsell, L. W., Studies in fat metabolism. I. The colorimetric determination of ketone bodies in biological fluids. J. Clin. Invest., 1951, 30, 1483.

4. Fiske, C. H., and SubbaRow, Y., The colorimetric determination of phosphorus. J. Biol. Chem., 1925,66, 375.

5. Giragossintz, G. D., Davidson, C., and Kirk, P. L., The microdetermination of blood sugar by ceric sulphate titration. Mikrochemie, 1936, 21, 21.

6. Randolph, T. G., Differentiation and enumeration of eosinophils in the counting chamber with a glycol stain; a valuable technique in appraising $\mathrm{ACTH}$ dosage. J. Lab. \& Clin. Med., 1949, 34, 1696. 